\title{
Polymorphism of exon 2-3 of bovine major histocompatibility complex class I BoLa-A gene
}

\author{
Bharat Bhushan ${ }^{1}$, Biswa Nath Patra ${ }^{1}$, Pranab Jyoti Das ${ }^{1}$, Triveni Dutt ${ }^{2}$, Pushpendra Kumar ${ }^{1}$, Arjava Sharma ${ }^{1}$, \\ Umang $^{1}$, Satyabarta Dandapat ${ }^{3}$ and Shiv Pal Singh Ahlawat ${ }^{1}$ \\ ${ }^{1}$ Genetic Marker Laboratory, Animal Genetics Division, Indian Veterinary Research Institute, \\ Izatnagar, Bareilly, Uttar Pradesh, India. \\ ${ }^{2}$ Livestock Production and Management Section, Indian Veterinary Research Institute, Izatnagar, \\ Bareilly, Uttar Pradesh, India. \\ ${ }^{3}$ Division of Animal Biotechnology, Indian Veterinary Research Institute, Izatnagar, Bareilly, \\ Uttar Pradesh, India.
}

\begin{abstract}
The exon 2-3 region of bovine major histocompatibility complex (MHC) class I BoLa-A gene was investigated for polymorphisms in three breeds of cattle originated in the Indian subcontinent namely Sahiwal, Tharparkar, Hariana, as well as crossbred (Bos taurus $x$ Bos indicus) cattle and Jersey, the exotic breed (Bos taurus). The PCR amplified fragment of 714 bp showed distinct Ddel-, Taql- and Hinfl- RFLP patterns, thus confirming a higher degree of polymorphism in this region. To our knowledge this is the first report of Hinfl restriction patterns for BoLa-A exon 2-3. The sequencing results revealed a number of nucleotide substitutions in this region, which resulted in amino acid changes. The present investigation confirmed that MHC class I BoLa-A exon 2-3 is highly polymorphic in cattle.
\end{abstract}

Key words: MHC, BoLa-A polymorphism, cattle.

Received: November 28, 2005; Accepted: June 5, 2007.

The major histocompatibility complex (MHC) is a chromosomal region consisting of a series of closely linked loci or so called gene families. The MHC of cattle is known as bovine lymphocyte antigen (BoLa) located on chromosome 23 . Two molecularly well-defined classes of cell surface antigens are present among the gene products of the MHC region. Class I antigens are found on the surface of nearly all cell types and are in general involved in the cytotoxic T-cell response. These antigens are highly polymorphic and their amino acid sequences are highly variable. These variations are concentrated in three to four discrete hypervariable regions within the $\alpha 1$ and $\alpha 2$ domains. The rest of the molecule is highly conserved and shows little sequence variation. At present, only one class I locus (BoLa-A) is internationally accepted on the basis of serological testing, although there is evidence for the existence of a second class I locus (BoLa-B). Molecular analysis of MHC class I region suggested that this region may contain up to 15 genes. The BoLa-A locus has 32 serologi-

Send correspondence to Bharat Bhushan. Genetic Marker Laboratory, Animal Genetics Division, Indian Veterinary Research Institute, Izatnagar, 243122 Bareilly, India. E-mail: bb@ivri.up.nic.in and bbhuhan_ivri2003@yahoo.co.in. cally defined alleles and at least four more putative alleles, in addition to a high frequency of null alleles (Tizard, 1998). Sequencing of the expressed class I genes from serologically typed animals showed that single BoLa-A types can be expressed up to three class I genes and that BoLa specificity is associated with one gene product (Ellis et al., 1996, 1999). Thus, BoLa-A typing defines a class I haplotype rather than an allele. This demonstrates that the limitations of serological typing go beyond its breed-specific nature and shows that there is need for methods that will allow class I polymorphism to be analyzed directly, i.e. at DNA level (Sawhney et al., 2001). Ellis et al. (1998) described the DNA based typing of BoLa class I gene using sequence specific amplification of expressed class I alleles from cDNA for a few European haplotypes. The wider application of this method is limited by the lack of information on class I allele sequence variation between breeds and by breed-specific differences in the class I types represented (Bull et al., 1989). Analysis of MHC class II polymorphism has benefited from the development of PCR-RFLP methods, which have improved the ease and reliability of class II typing (van Eijk et al., 1992; Ballingall et al., 1997). However, the development of PCR based typ- 
ing techniques for class I genes is complicated by the expression of multiple class I genes in most haplotypes and the lack of obvious sequence differences between these genes (Ellis et al., 1999). Thus, designing of primer sequences is limited to the available DNA sequences and is not locus-specific. The primers used for amplification were within the conserved regions at the start of exon 2 and the end of exon 3. As the primers incorporate all the polymorphism observed in the class I sequences, they were expected to amplify the majority of expressed class I genes. Considering the importance of BoLa-A gene in controlling immune responses, the present investigation was conducted to characterize the exon 2-3 region of this gene in cattle populations.

Investigations were undertaken on Sahiwal $(\mathrm{n}=56)$, Tharparkar $(\mathrm{n}=25)$, Hariana $(\mathrm{n}=14)$ and crossbred $\{$ Bos taurus (Holstein Friesian) $x$ Bos indicus (Hariana) $\}$ cattle $(\mathrm{n}=70)$ of Indian origin and on an exotic (Bos taurus) Jersey $(n=18)$ cattle breed maintained at various organized livestock farms of the country. Genomic DNA was isolated from $5 \mathrm{~mL}$ of venous blood collected from the jugular vein by phenol-chloroform extraction method.

A $714 \mathrm{bp}$ fragment encompassing exon 2-3 region of MHC Class I BoLa-A gene was amplified (Figure 1a) with the forward and reverse primers 5'-GTC CCC ACT CSM TGA GGT ATT-3' and 5'-TCC AGG TAT CTG CGG AGC-3', respectively, as previously described (Sawhney et al., 2001). PCR was carried out in the final volume of $50 \mu \mathrm{L}$ containing $100 \mu \mathrm{M}$ dNTPs mix, $200 \mathrm{ng}$ of each primer, $5 \mu \mathrm{L}$ of $10 \mathrm{x}$ PCR assay buffer, $3 \mu \mathrm{L} \mathrm{MgCl}_{2}(2.5 \mathrm{mM}), 1$ unit of Taq DNA polymerase and 80-100 ng of genomic DNA. The amplification of the 714 bp product was carried out using a thermal cycler (PTC-200, MJ Research) under the following conditions: $94^{\circ} \mathrm{C}$ for $3 \mathrm{~min}$, followed by 35 cycles of $94^{\circ} \mathrm{C}$ for $40 \mathrm{~s}, 58^{\circ} \mathrm{C}$ for $40 \mathrm{~s}$ and $72^{\circ} \mathrm{C}$ for $1 \mathrm{~min}$. The final extension was done at $72{ }^{\circ} \mathrm{C}$ for $5 \mathrm{~min}$. The PCR products were checked by agarose gel electrophoresis. For each sample, $10 \mu \mathrm{L}$ of PCR product was digested with 5 units of each restriction enzyme (DdeI, TaqI, and Hinfl). Samples digested with $T a q \mathrm{I}$ were incubated at $65^{\circ} \mathrm{C}$, whereas samples digested with $D d e I$ and $\operatorname{Hinfl}$ were incubated at $37^{\circ} \mathrm{C}$ overnight. The DdeI and TaqI digested restriction fragments were resolved on $8 \%$ polyacrylamide gels and visualized by silver staining. The Hinfl digested restriction fragments were resolved by $3 \%$ agarose gel electrophoresis, stained with ethidium bromide and documented by means of the Gel Documentation System (Syngene, U.K.). Purified PCR products extracted from the gel were ligated into the cloning vector $\mathrm{pTZ} 57 \mathrm{R} / \mathrm{T}$, according to the manufacturer's recommendations (MBI Fermentas), with some modifications. A $20-30 \mathrm{~min}$ extension at $72{ }^{\circ} \mathrm{C}$ resulted in a 3-4 folds higher yield of recombinant colonies of host cell E. coli strain DH5 $\alpha$. The inserts were confirmed by colony PCR and restriction digestion of plasmids with PstI and EcoRI, yielding a fragment of $762 \mathrm{bp}$. Automated sequenc- ing of the clones was carried out using M13 forward and reverse primers (ABI PRISM) and sequencing data were analyzed by the program DNAstar (Thompson et al., 1994).

DdeI digestion of the PCR-amplified 714 bp fragment produced five novel fragments, in addition to those already reported by Sawhney et al. (2001). The fragment sizes of A10, A11, A18, A19, A20 and A31 BoLa-A types were 440, 380 bp; 380 bp; 440, 230, 170, 135 bp; 480, 380, $95 \mathrm{bp} ; 320,300,250 \mathrm{bp}$ and 230, $170 \mathrm{bp}$, respectively (Figure 1b). Two novel patterns with fragment sizes of 603, 99, $12 \mathrm{bp}$ and $600,60,39,12 \mathrm{bp}$ in crossbred cattle, were later confirmed by cloning and sequencing. Digestion with Taq $\mathrm{I}$ also revealed the specific fragments of BoLa-A alleles as reported by Sawhney et al. (2001), 300 and 250 bp for A10, 475 and $75 \mathrm{bp}$ for A11; $70 \mathrm{bp}$ for A18; 430 and $115 \mathrm{bp}$ for A31, respectively (Figure 1c). Three new patterns with fragment sizes of $605,106 \mathrm{bp} ; 608,68,38 \mathrm{bp}$ and 532, 106, $76 \mathrm{bp}$ in crossbred cattle were confirmed by cloning and sequencing. The 470 and $75 \mathrm{bp}$ fragments of BoLa-A19 type reported by Sawhney et al. (2001) were not observed after Taq I digestion, indicating the absence of this restriction site for BoLa-A19 type in the present investigation.

Sawhney et al. (2001) reported that the DdeI patterns with the largest number of bands revealed at least five BoLa-A types. The presence of conserved and polymorphic bands in all investigated animals supports the view that the functional, i.e. expressed and polymorphic class I genes, were produced by PCR-RFLP. Additionally, the pattern of $D d e \mathrm{I}$ and $T a q \mathrm{I}$ conserved bands formed a framework within which the polymorphic bands could be easily identified. Sawhney et al. (2001) also observed that TaqI and $D d e$ I produced a number of BoLa-A type specific bands and unique combinations for most of the seven BoLa-A types. Ellis et al. (1999) confirmed that the A11 BoLa-A type comprises multiple polymorphic class I genes and includes the two TaqI fragments assigned as A11 specific (470, 75 bp), but did not show the $380 \mathrm{bp} D d e$ I fragment.

The frequencies of BoLa-A types in the present study ranged from 0.015 to 0.722 , with wide variation among different breeds of cattle (Table 1). These results revealed that the A10/A19, A10/A31, A18/A20 and A20/A31 BoLa-A types were similar to those reported by Sawhney et al. (2001). Ten BoLa-A types were reported (A18/A31, A10/A19, A10/A31, A18/A20, A10/A11, A20/A31, A31/A32, A11/A20, A11/A32 and A19/A20) (Sawhney et al. 2001) out of which A10/A19, A10/A31, A20/A31, A31/A32, A11/A20 and A11/A32 were already recognized in the $5^{\text {th }}$ International Bovine Lymphocyte Antigen (BoLa) Workshop and were assigned the workshop ID numbers WK5-38, WK5-53, WK5-51, WK5-36, WK5-29 and WK5-48, respectively (Davies et al., 1994). Besides, other BoLa-A types (A18/A19 and A19/A31) revealed the high degree of polymorphism in cattle population.

Digestion of the $714 \mathrm{bp}$ fragment with Hinfl produced patterns specific to BoLa-A types, which were named as A, 

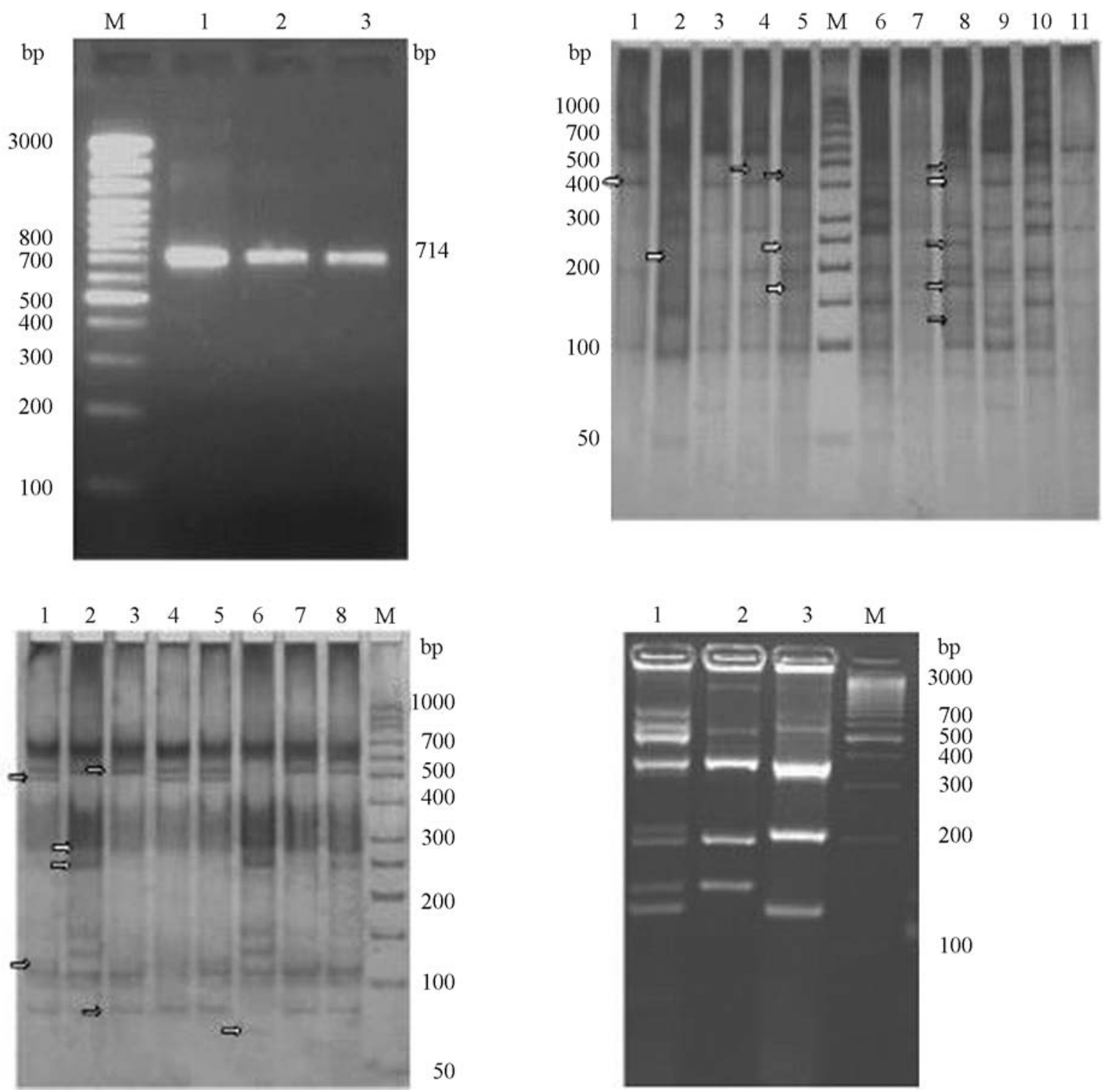

Figure 1 - PCR-RFLP results of exon 2-3 region of MHC class I BoLa-A gene in cattle. (a). PCR amplified products. Lane M: 100 bp DNA ladder, Lanes 1, 2 and 3: 714 bp PCR products; (b). DdeI restriction patterns. Lane M: 50 bp DNA ladder; Lanes 1, 3, 9 and 11: Allele A11; Lane 2: Allele A18/19; Lanes 4, 6 and 10: Allele A19; Lane 5: Allele A11/A18; Lane 7: Allele A18; Lane 8: Allele A10/18; (c). TaqI restriction patterns. Lane M: 50 bp DNA ladder; Lanes 1, 4 and 5: Allele A31; Lanes 2 and 8: Allele A10; Lanes 3 and 7: Allele A19 or A11; Lane 6: Allele A18; (d). Hinfl restriction patterns. Lane M: 100 bp DNA ladder; Lane 1: Allele AB; Lane 2: Allele BB; Lane 3: Allele AA.

B, C, D and E (Figure 1d) after validation by sequencing. It was observed that most of the cattle populations were heterozygous. The fragment sizes of patterns A, B, C, D and E were 122, 212, $379 \mathrm{bp} ; 141,193,379 \mathrm{bp} ; 71,122,142$, $379 \mathrm{bp} ; 379,275,60 \mathrm{bp}$ and 335, $380 \mathrm{bp}$, respectively. To our knowledge this is the first report of Hinfl restriction patterns for BoLa-A exon 2-3.

Sequencing revealed that the sizes of the exon 2-3 fragments ranged between 711 to $714 \mathrm{bp}$ in crossbred cattle (GenBank accession numbers AY894412, AY894413 and AY894414). This variation in nucleotide number was due to the addition and deletion of bases. Exon 2 with $267 \mathrm{bp}$
(AY790631), encoding 89 amino acids, showed a large number of amino acid changes. It was also seen that the reading frame shifted because of two base pair deletions at positions 216 and 217, and maximum nucleotide changes occurred in three clusters. Polymorphism in exon 2 occurred mostly due to nucleotide base changes at the positions from 61 to 72,121 to 138 and 184 to 231, whereas nucleotides from 238 to 269 were conserved. Intron 2 followed by exon 2 with sequence GGTGAG had more frequent nucleotide substitutions than exon 2. Exon 3 initiated at nucleotide 468 and had the purine-rich conserved sequence CGGGTCA (AY790632). More base changes 
made this region highly polymorphic. The comparison of MHC exon 2 and 3 sequences of crossbred cattle (Bos taurus $\mathrm{x}$ Bos indicus) and Holstein Friesian (Bos taurus) is shown in Table 2. The closest sequences of exon 2 and 3 of crossbred cattle differed by 10 and 8 amino acids, respectively in comparison to the Holstein Friesian sequence. The nucleotide substitutions and nucleotide identity ranged from 14 to 40 bases and $82.6 \%$ to $92.9 \%$, respectively, for exons 2 and 12 , to 29 bases and $88.4 \%$ to $93.3 \%$, respectively for exon 3 . The addition of two bases and the deletion of two bases in exon 2, as well as the deletion of three bases in exon 3 were also observed.

A phylogenetic tree analysis was performed by aligning the sequences of the BoLa-A exon 2-3 (GenBank accession numbers AY790631, AY790631, AY894412, AY894413 and AY894414) with BuLa-A exon 2-3 (GenBank accession numbers AY894407, AY894408 and AY925136) and Holstein Friesian sequences available in the GenBank (Accession numbers X97645 and X97646). The phylogenetic tree based on nucleotide sequences of exon 2 and 3 showed differences in proximity of the related

Table 1 - Frequencies of BoLa-A types of exon 2-3 in various cattle breeds.

\begin{tabular}{|c|c|c|c|c|c|}
\hline Breed & $\begin{array}{c}\text { BoLa-A } \\
\text { type }\end{array}$ & Frequency & Breed & $\begin{array}{c}\text { BoLa-A } \\
\text { type }\end{array}$ & Frequency \\
\hline $\begin{array}{l}\text { Hariana } \\
(\mathrm{n}=14)\end{array}$ & $\begin{array}{l}\text { A10 } \\
\text { A11 } \\
\text { A18 } \\
\text { A19 } \\
\text { A10/A11 }\end{array}$ & $\begin{array}{l}0.055 \\
0.055 \\
0.055 \\
0.722 \\
0.111\end{array}$ & $\begin{array}{l}\text { Tharparkar } \\
(\mathrm{n}=25)\end{array}$ & $\begin{array}{l}\text { A10 } \\
\text { A11 } \\
\text { A18 } \\
\text { A19 } \\
\text { A31 } \\
\text { A10/A19 } \\
\text { A10/A20 } \\
\text { A10/A31 } \\
\text { A18/A19 } \\
\text { A19/A31 }\end{array}$ & $\begin{array}{l}0.037 \\
0.037 \\
0.148 \\
0.259 \\
0.111 \\
0.111 \\
0.074 \\
0.037 \\
0.037 \\
0.148\end{array}$ \\
\hline $\begin{array}{l}\text { Sahiwal } \\
(\mathrm{n}=56)\end{array}$ & $\begin{array}{l}\text { A10 } \\
\text { A11 } \\
\text { A19 } \\
\text { A31 } \\
\text { A10/A11 } \\
\text { A10/A18 } \\
\text { A10/A19 } \\
\text { A10/A31 } \\
\text { A11/A18 } \\
\text { A18/A20 } \\
\text { A19/A20 } \\
\text { A19/A31 } \\
\text { A20/A31 } \\
\text { NEW* } \\
\text { NEW** }\end{array}$ & $\begin{array}{l}0.054 \\
0.036 \\
0.304 \\
0.054 \\
0.018 \\
0.054 \\
0.214 \\
0.018 \\
0.036 \\
0.018 \\
0.018 \\
0.054 \\
0.071 \\
0.018 \\
0.036\end{array}$ & $\begin{array}{l}\text { Crossbred } \\
(\mathrm{n}=70)\end{array}$ & $\begin{array}{l}\text { A10 } \\
\text { A11 } \\
\text { A18 } \\
\text { A19 } \\
\text { A31 } \\
\text { A10/A18 } \\
\text { A10/A19 } \\
\text { A11/A18 } \\
\text { A11/A31 } \\
\text { A18/A19 } \\
\text { A19/A31 }\end{array}$ & $\begin{array}{l}0.058 \\
0.103 \\
0.088 \\
0.265 \\
0.074 \\
0.015 \\
0.074 \\
0.015 \\
0.029 \\
0.206 \\
0.074\end{array}$ \\
\hline & & & $\begin{array}{l}\text { Jersey } \\
(\mathrm{n}=18)\end{array}$ & $\begin{array}{l}\text { A10 } \\
\text { A11 } \\
\text { A19 } \\
\text { A10/ A11 } \\
\text { A10/ A19 } \\
\text { A10/ A31 }\end{array}$ & $\begin{array}{l}0.315 \\
0.368 \\
0.105 \\
0.105 \\
0.052 \\
0.052\end{array}$ \\
\hline
\end{tabular}

New patterns: *DdeI $607,285,198,150,129,100$ bp. ${ }^{* *} D d e I$ 600, $100 \mathrm{bp})$. alleles (Figures 2a, 2b, 3a and 3b). The results further revealed that the nucleotide dissimilarity ranged from 1.1 to $17.9 \%$ for exon 2 and 0.0 to $20.9 \%$ for exon 3 .

The phylogenetic tree analysis revealed that the exon 2 sequences of crossbred cattle (AY894412) and Murrah buffalo (AY894407) cluster together on one branch showing the close proximity between these two species. These two sequences of exon 2 were found closest to Holstein Friesian sequence (X97645). One exon 2 sequence of crossbred cattle (AY894413) was found in a completely separate cluster when compared to the other sequences of cattle and buffalo of this region. In the case of exon 3, two

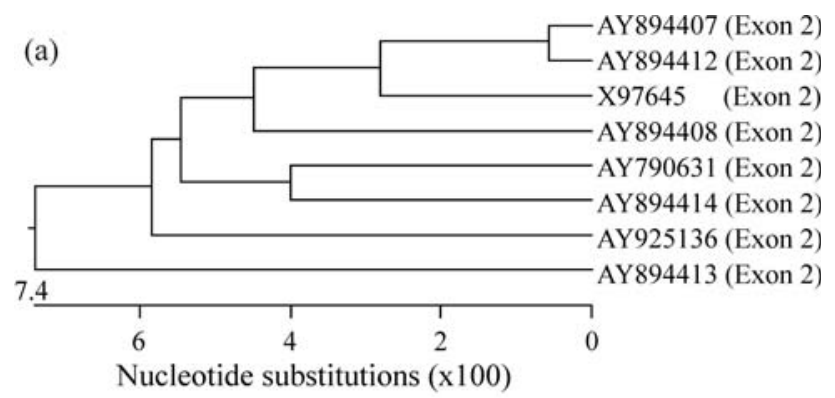
Percent identity
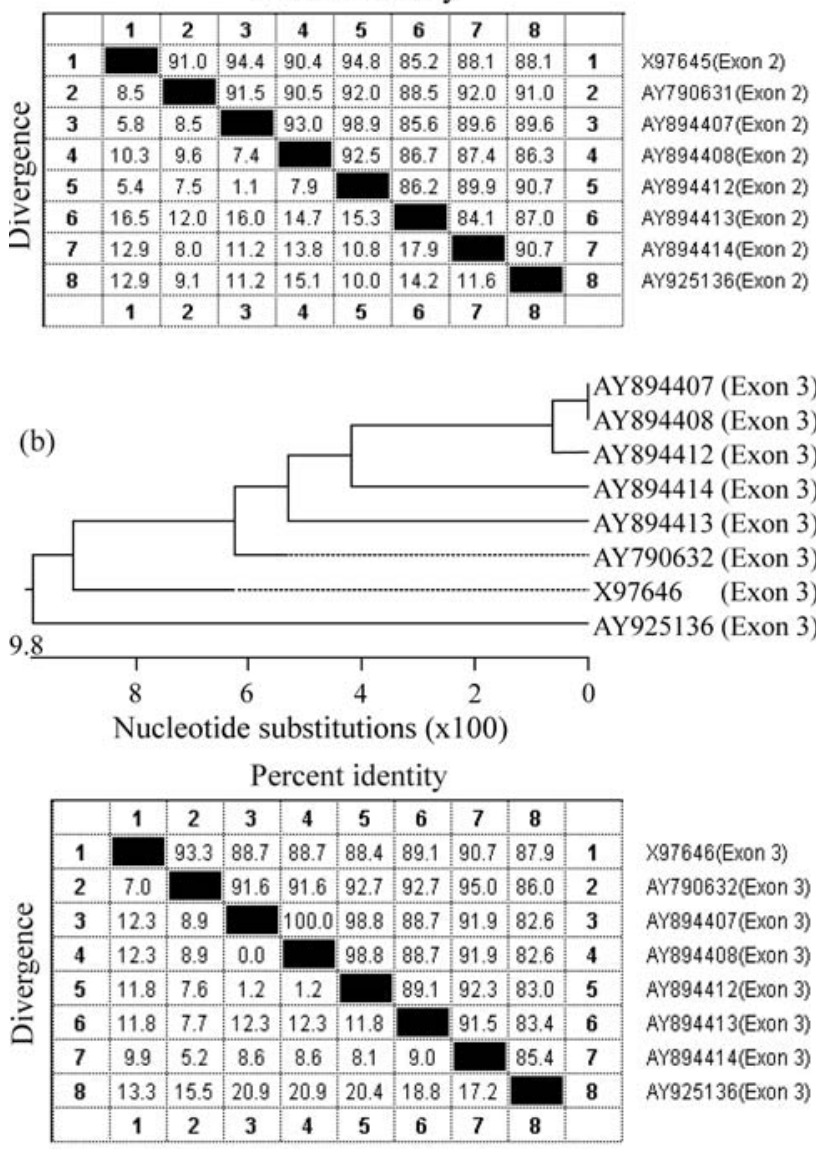

Figure 2 - Phylogenetic tree analysis using ClustalW methods with sequence distance table in the Magalign program in DNAstar using MHC class I (BoLa-A) nucleotide sequences of crossbred cattle, Holstein Friesian cattle and Murrah buffaloes. (a) Phylogenetic tree analysis of exon 2; (b) phylogenetic tree analysis of exon 3. 
Table 2 - Comparison of MHC class I (BoLa-A types) exon 2 and 3 sequences of crossbred (Bos taurus $x$ Bos indicus) and Holstein Friesian (Bos taurus) cattle.

\begin{tabular}{lcccc}
\hline $\begin{array}{l}\text { GenBank accession } \\
\text { number }\end{array}$ & $\begin{array}{c}\text { BoLa-A amino acid } \\
\text { substitutions }\end{array}$ & $\begin{array}{c}\text { BoLa-A amino acid } \\
\text { identity (\%) }\end{array}$ & $\begin{array}{c}\text { BoLa-A nucleotide } \\
\text { substitutions }\end{array}$ & $\begin{array}{c}\text { BoLa-A nucleotide } \\
\text { identity (\%) }\end{array}$ \\
\hline Exon 2 & 12 & & & \\
AY790631 & 10 & 81.8 & $17(1$ bp addition) & 88.0 \\
AY894412 & 23 & 88.8 & $14(2$ bp deletion $)$ & 92.9 \\
AY894413 & 19 & 74.2 & 40 & 82.6 \\
AY894414 & - & 78.7 & 32 & 86.3 \\
X97645 & 8 & - & - & - \\
Exon 3 & 19 & 86.4 & 12 & 93.3 \\
AY790632 & 15 & 76.5 & 29 & 88.4 \\
AY894412 & 15 & 81.5 & $27(3$ bp deletion $)$ & 88.9 \\
AY894413 & - & 81.5 & 23 & 90.3 \\
AY894414 & - & - & - & - \\
X97646 & & & & \\
\hline
\end{tabular}

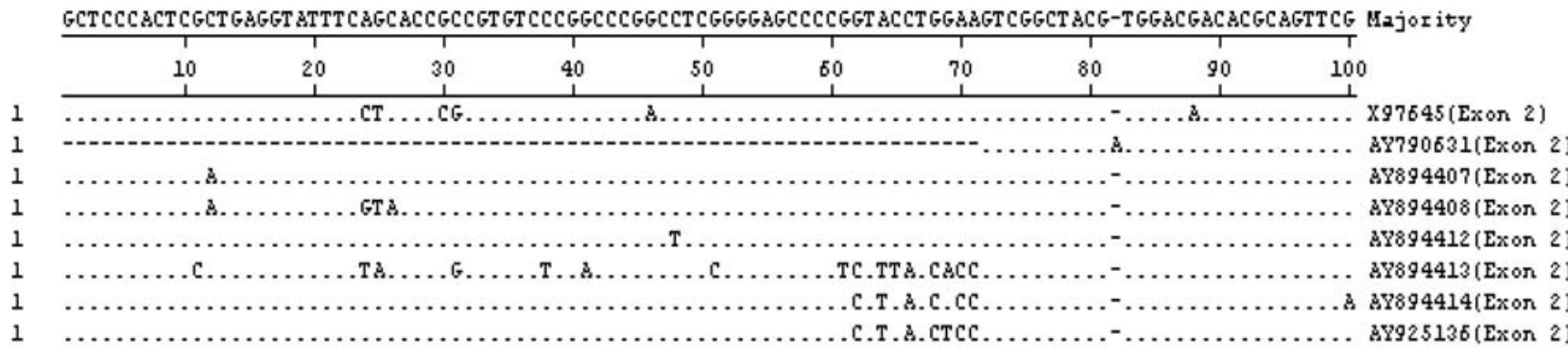

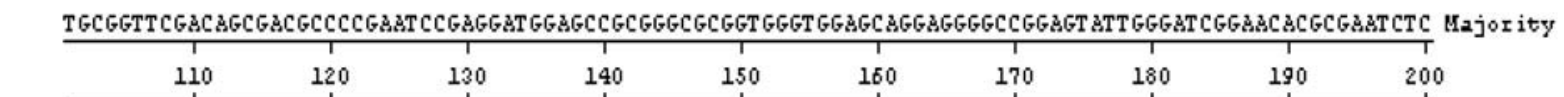

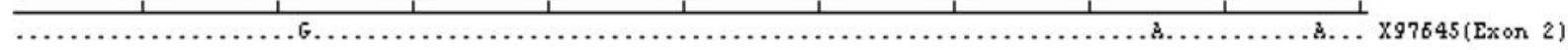

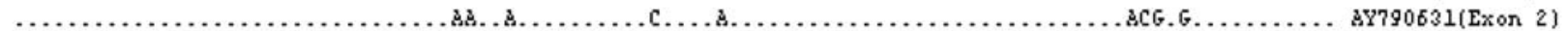

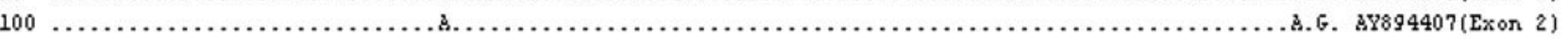

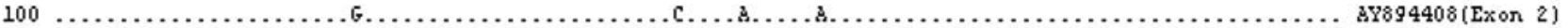

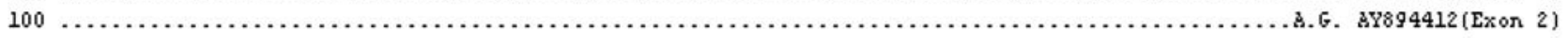

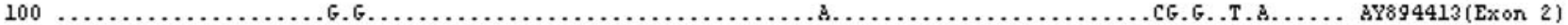

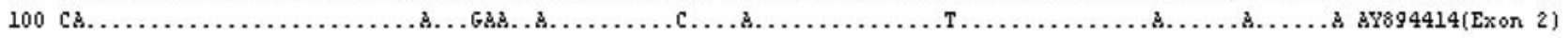

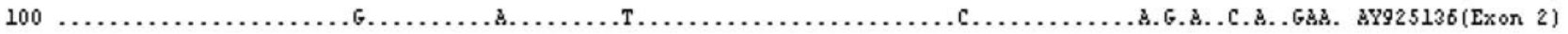

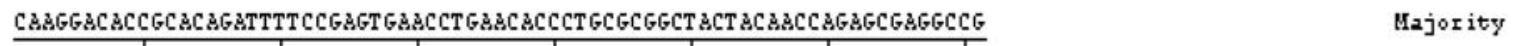

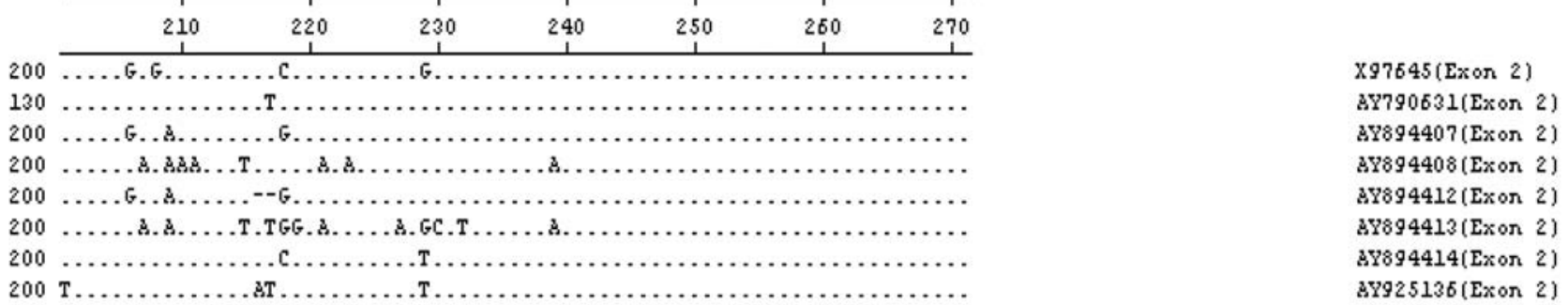

Figure 3a - Sequence alignment using ClustalW methods with Magalign program in DNAstar using MHC class I (BoLa-A) nucleotide sequences of crossbred cattle, Holstein Friesian cattle and Murrah buffaloes of exon 2.

sequences each of Murrah buffaloes (AY894407 and AY894408) and crossbred cattle (AY894412 and AY894413) formed the same cluster, showing the closeness of this region in cattle and buffalo. In contrast, the Hol- stein Friesian sequence (X97646) of exon 3 was found in a distinct branch, showing that in exon 2 Bos taurus was much closer to crossbred cattle and Murrah boffaloes (Bubalus bubalis) than in exon 3. One sequence of Murrah 


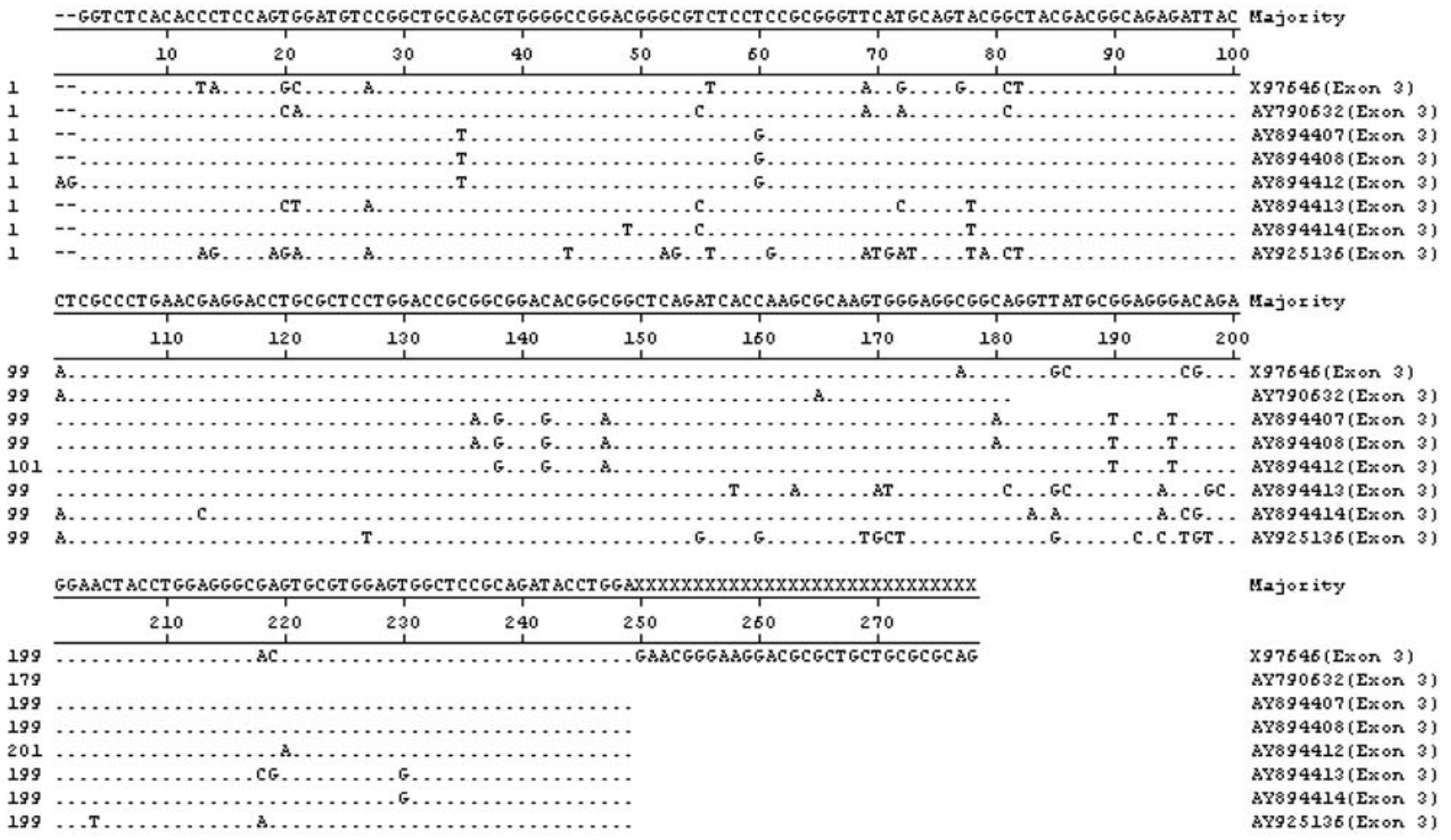

Figure 3b - Sequence alignment using ClustalW methods with Magalign program in DNAstar using MHC class I (BoLa-A) nucleotide sequences of crossbred cattle, Holstein Friesian cattle and Murrah buffaloes of exon 3.

buffalo (AY925136) was found on completely distant branch. Our finding of a lack of a polyphyletic lineage for the cattle and buffalo alleles does not support the transspecies persistence of allelic lineages in BoLa-A and BuLA-A. However, Bussche et al. (1999) reported transspecies persistence of allelic lineage in DRB alleles. The results of the present study support the finding of Brunsberg et al. (1996) of a characteristic patchwork pattern in DRB alleles, which can be explained as shared ancestral sequences.

This study confirms the polymorphic nature of exon 2-3 of the MHC class I BoLa-A gene as revealed by DdeI and TaqI RFLPs, and describes the patterns of HinfI RFLPs. Sequencing revealed additions, deletions and substitutions of bases in exons 2-3, producing a high degree of polymorphism in the gene.

\section{Acknowledgments}

The authors are thankful to the Director and Joint Director (Academic) of the Indian Veterinary Research Institute (IVRI), Izatnagar for providing the facilities to conduct the study. The help received from Incharge, Livestock Production Management Section, IVRI, Izatnagar, UP; Livestock Research Center, GBPUA\&T, Pantnagar, Uttaranchal; Central Cattle Breeding Farm, Suratgarh, Rajasthan and College of Veterinary Sciences \& Animal Husbandry, Mathura, UP, India for collection of the blood samples of cattle is also duly acknowledged.

\section{References}

Ballingall KT, Luyai A and Mckeever DJ (1997) Analysis of genetic diversity at the DQA locus in African cattle: Evidence for a DQA3 locus. Immunogenetics 46:237-44.

Brunsberg U, Lilja IE, Andersson L and Gustafsson K (1996) Structural and organization of pig MHC class II DRB genes: Evidence for genetic exchange between loci. Immunogenetics 44:1-8.

Bull RW, Lewin HA, Wu MC, Peterbaugh K, Antczak D, Bernoco D, Cwik S et al. (1989) Joint report of the third international bovine lymphocyte antigen (BoLA) workshop, Helsinki, Finland. Anim Genet 20:109-32.

Bussche RAV, Hoofer SR and Lochmiller RL (1999) Characterization of MHC-DRB allelic diversity in white tail deer (Odocoileus virginianus) provides insight into MHC-DRB allelic evolution within cervidae. Immunogenetics 49:429437.

Davies CJ, Joosten I, Bernoco D, Arriens MA, Bester J, Ceriotti G, Ellis S, et al. (1994) Polymorphism of bovine MHC class I genes. Joint report of the fifth international bovine lymphocyte antigen (BoLA) workshop, Interlaken, Switzerland. Eur J Immunogenet 21:239-258.

Ellis SA, Holmes EC, Staines KA, Smith MJ, McKeever DJ, MacHugh ND and Morrison WL (1999) Variation in the number of expressed MHC genes in different cattle class I haplotypes. Immunogenetics 50:319-328.

Ellis SA, Staines KA and Morrison WL (1996) cDNA sequence of cattle MHC class I genes transcribed in serologically defined haplotypes A18 and A31. Immunogenetics 43:156159. 
Ellis SA, Staines KA, Stear MJ, Hensen EJ and Morrison WL (1998) DNA typing for BoLA class I using sequencespecific primers (PCR-SSP). Eur J Immunogenet 25:365-70.

Sawhney SMS, Taylor DW and Russell GC (2001) Polymorphism of bovine major histocompatibility complex (MHC) class I genes revealed by polymerase chain reaction (PCR) and restriction enzyme analysis. Anim Genet 32:27-31.

Thompson JD, Higgins DG and Gibson TJ (1994) CLUSTAL W: Improving the sensitivity of progressive multiple sequence alignment through sequence weighting, position-specific gap penalties and weight matrix choice. Nucleic Acids Res 22:4673-4680.
Tizard IR (1998) Veterinary Immunology: An Introduction. $5^{\text {th }}$ edition. Harcourt Brace and Company, San Diego, 482 pp.

van Eijk MJT, Stewart- Haynes JA and Lewin HA (1992) Extensive polymorphism of the BoLA-DRB3 gene distinguished by PCR-RFLP. Anim Genet 23:483-496.

\section{Internet Resource}

GenBank: http://www.ncbi.nlm.nih.gov/Entrez, nucleotide sequences (AY790631, AY790632, AY894412, AY894413, AY894414).

Associate Editor: Pedro Franklin Barbosa 